\title{
AS MANOBRISTAS DA ÁGUA NA COMUNIDADE DA ROCINHA Uma questão de gênero e direitos humanos
}

\author{
WATER MANUFACTURERS IN THE ROCINHA COMMUNITY \\ A question of gender and human rights
}

\author{
Marianina Impagliazzo \\ Geógrafa/Cartógrafa pela UFRJ, Mestra pela UERJ, Doutora pela UFRJ. Membro do corpo docente do Centro \\ Universitário Inta - UNINTA/Ceará. mimpagliazzo@gmail.com
}

\begin{abstract}
RESUMO
O estudo se apóia conceitualmente nas reflexões de Herrera Flores buscando a compreensão do direito humano à água como um produto cultural, o conceito polissêmico de Território segundo Milton Santos e os postulados do Ecofeminismo cunhado por Françoise d’Eaubonne. O lócus é a Comunidade da Rocinha no Município do Rio de Janeiro e os sujeitos são as manobristas das águas, mulheres moradoras locias. O objetivo é discorrer sobre a participação das mulheres relacionadas ao uso do recurso, sua participação na gestão comunitária até então somente adstrita aos homens, reconhecendo como direito fundamental à vida com dignidade hidro-sanitária. A negação plena ou parcial ao acesso da à agua, fere frontalmente o artigo 225 da Constituição brasileira de 1988 e os artigos 3 e 8 do Conselho de Direitos Humanos (CDH) em setembro de 2010 .
\end{abstract}

\begin{abstract}
The study is conceptually based on the reflections of Herrera Flores seeking to understand the human right to water as a cultural product, the polysemic concept of Territory according to Milton Santos and the postulates of Ecofeminism coined by Françoise d'Eaubonne. The locus is the Community of Rocinha in the Municipality of Rio de Janeiro and the subjects are the water valets, local women residents. The objective is to discuss the participation of women related to the use of the resource, their participation in community management until then only assigned to men, recognizing as a fundamental right to life with hydro-sanitary dignity. The full or partial denial of access to water directly violates article 225 of the Brazilian Constitution of 1988 and articles 3 and 8 of the Human Rights Council (CDH) in September 2010.
\end{abstract}

Palavras-chave: Direitos Humanos; Água Potável;Comunidade da Rocinha;Mulheres Manobristas.

Key words: Human Rights; Drinking Water; Community of Rocinha; Women Valets.

\section{INTRODUÇÃO}

A Rocinha é uma favela localizada no Município do Rio de Janeiro, contando com 130 mil habitantes segundo registros do ano de 2020 da concessionária responsável pela distribuição de energia elétrica. É uma comunidade de alto risco social que cresce sem nenhuma regularização dos terrenos pelo poder público, que sofre com a falta ou a irregularidade no fornecimento de água apesar das seis elevatórias e três reservatórios em operação no local (DA SILVA,2020).

Atualmente o abastecimento ficou mais prejudicado e irregular decorrente do cancelamento do "Programa Comunidade Cidade" pelo atual governo interino do Estado e a Companhia Estadual de Águas e Esgotos do Rio de Janeiro (CEDAE) que realiza manutenção nos três reservatórios, Navio, Terreirão e Laboriaux, enfatiza que não tem condições de abastecer todas as casas de forma regular devido ao crescimento exponencial das moradias e vielas que dificultam o cálculo do volume para fornecimento.

Neste cenário de descaso pelo poder público surge na Comunidade da Rocinha uma experiência sui generis de gestão da distribuição de água na comunidade,as mulhres manobristas,que intuitivamente desenvolveram uma pedagogia comunitária e local para cuidar e fornecer o recurso de forma 
igualitária. São denominadas "técnicas" que realizam manobras no fluxo de água e reparos em canos que se perdem em meio aos becos e vielas, trabalhando sob demanda e não sendo reconhecidas tanto pela CEADE quanto pelo Estado.

No último Censo Domiciliar na Rocinha, foi constatado que 47,4\% das famílias são compostas por até 6 membros, sendo que 62,5\% possuem de 1 a 4 filhos e, $78 \%$ das famílias são formadas por mulheres, chefes de família, com mais de um filho e o sustento de $52 \%$ das famílias é fruto do trabalho de diarista ou de lavagem e passagem de roupa. As mulheres manobristas surgem dessa imposição ao sustento e sobrevivência em uma comunidade vulnerável com escassez de um recurso fundamental à dignidade humana (DA SILVA,2020).

A condição de invisibilidade dessas mulheres e seu comando passam por valores ecológicos e sociais, trabalhando em locais insalubres, físico e moralmente, sem nenhum alento sequer. Ocupando as obrigações que deveriam ser de competência pública, dão conta de tudo e todas com valores e percepções femininos pouco observados e acatados pelos pares masculinos (MERLO; CALGARO, 2021).

\section{METODOLOGIA}

O estudo parte das reflexões de Flores (2002) que propõe um novo olhar sobre a temática buscando a compreensão do direito humano à água como um produto cultural, o conceito polissêmico de Território de Santos (1994) como um espaço delimitado pelas relações de poder formado por superfícies com estruturas econômicas, políticas e culturais, por linhas como redes e por pontos focais definidos por lugares. Para o entendimento dos postulados do Ecofeminismo nos apoiamos em d’Eaubonne (2020).

O trabalho está estruturado sob o método materialista-dialético de pesquisa que se caracteriza pelo movimento do pensamento através da materialidade histórica da vida dos homens em sociedade. Foi realizada uma de revisão integrativa de literatura com finalidade sintetizar resultados obtidos em pesquisas sobre o tema, de maneira sistemática, ordenada e abrangente. Saídas de campo foram realizadas, para nos permitir investigar em uma dimensão interdisciplinar a organização do espaço geográfico, além de entrevistas e questionários que foram aplicados aos sujeitos (GIL, 2010).

De caráter exploratório foram utilizados fatos e teorias para revelar a importância da temática, tratando o direito humano à água potável reconhecido pela Assembleia Geral da Organização das Nações Unidas (ONU) como parte do direito internacional vinculante em 2010.

\subsection{Objetivos}

A investigação tem o objetivo de discorrer sobre a participação das mulheres relacionadas ao uso do recurso, sua participação na gestão comunitária até então somente adstrita aos homens, reconhecendo como direito fundamental à vida com dignidade hidro-sanitária.

\subsection{Sujeitos e Lócus}

Moradoras do gênero feminino denominadas, manobristas das águas, da Comunidade da Rocinha localizada no Município do Rio de Janeiro. São no total de dez mulheres para atender a toda localidade, sem qualquer vínculo empregatício com a CEDAE, realizando as manobras de forma solidária para que o fornecimento e abastecimento sejam regulares e contínuos.

\subsection{Coleta e Análise}

Questionário contendo dez questões, sendo duas abertas e as demais fechadas, foi aplicado aos sujeitos da pesquisa para garantir a padronização e a comparação dos dados. As entrevistas como 
método de coleta permitiu um relacionamento direto com o grupo estudado obtendo o maior número de informações dos fatos.

As questões foram discutidas com o grupo de mulheres e os resultados foram apresentados de forma quantitativa e qualitativa. Os dados foram avaliados a partir das respostas para cada questionamento, os quais foram depois compilados e apresentados em forma de gráficos e/ou discutidas grupalmente.

\section{RESULTADOS E DISCUSSÃO}

Pela imposição da pandemia, as saídas à campo foram suspensas em abril de 2020, retomadas em junho de 2021 e foi constatado que desde final de 2019 perdura a privação da água aos moradores demonstrando a falta de políticas públicas de qualidade para esses locais como também o descaso do órgão responsável pelo abastecimento de água na comunidade.

Ao longo da convivência em campo, foi observado nitidamente com os moradores, a representação de negatividade da comunidade é tão evidente que passa a ser considerada como aglomerado subnormal pelo Instituto Brasileiro de Geografia e Estatística (IBGE) corroborando dessa maneira, para uma visão preconceituosa e discriminatória. Para Kuhn (2018) esse é um problema estrutural de longa data, a invisibilidade e o preconceito intensifica o descaso com as comunidades não assegurando a disponibilidade e gestão sustentável da água e saneamento para todos.

Foi constatado em campo que as condições sanitárias da Rocinha relegam a população local mais vulnerável à propagação de epidemias, demonstrando um descompasso entre as ações governamentais implementadas na região, por exemplo, com os investimentos nos eventos turísticos e comércio local sendo uma clara violação ao Estatuto da Cidade (Lei 10.257/2001).

As mulheres manobristas relataram nas entrevistas que atuaram intensamente durante a pandemia formando uma rede de apoio solidário, sendo a única alternativa para a manutenção da distribuição do recurso à comunidade, mantendo o sustento e sobrevivência de inúmeras famílias. Destacaram que apesar da existência de diversos grupos de resistência, Rocinha sem Fronteiras, Rocinha SOS Saneamento e Fórum de Cultura, que se empenham na mobilização dos moradores, o saneamento básico não faz parte da pauta de prioridades das autoridades do Município e do Estado.

Nas falas das manobristas, a CEDAE coloca a "favela" como a última a receber água mas " $a$ cobrança chega em dia todo mês", resaltando que no imaginário do resto da cidade os pobres não pagam água e assim podem viver sem o recurso. Para Rodrigues et al, nos agrupamentos considerados subnormais como o caso da Comunidade da Rocinha, deveria ser levado em consideração pelos gestores municipais o cálculo da adequação de domicílios para fins de monitoramento das metas de universalização do saneamento básico, o que geraria maior equidade na distribuição de recursos básicos e na geração de renda para os cofres públicos.

Relatam as manobristas que antes da pandemia o desabastecimento era uma constante e se agravou com a imposição do distanciamneto social e o lockdown na cidade, tendo que recorrerem a Defensoria Pública do Rio de Janeiro para o abastecimento por caminhões-pipa. Nas entrevistas, as manobristas reforçaram que apesar da CEDAE ter empreendido um programa emergencial de desinfecção das áreas comuns da comunidade - ruas, calçadas, praças - aplicando um produto que cria uma película protetora contra o vírus, foi só um "tapa boca", porque o importante e as reivindicações dos moradores era para a regularidade no abastecimento.

As respostas aos questionários reforçam que a "falta de água" na comunidade como em todas as comunidades de alto risco social é uma construção social da crise, quando sinalizam o abandono do debate sobre a desigualdade no acesso ao recurso persiste a muitas décadas e hoje reforçado pela 
possibilidade de privatização da CEDAE, fruto de uma chantagem que o governo federal vem realizando com o Estado do Rio de Janeiro, o qual depende de sua ajuda financeira para lidar com a crise econômica. As manobristas reforçaram nas questões abertas o que Pires do Rio et al em seus estudos alerta, que a circulação da água é parte integrante da circulação do capital e como outros bens é parte da economia política que estrutura relações de poder, que dá uma forma e uma coerência ao espaço urbano quando descrevem a exclusão historicamente vividas como uma escassez hidrossocial.

Swyngedouw \& Cook (2017) corroboram nas questões fechadas respondidas pelas manobristas que o crescimento sem planejamento da comunidade para a CEDAE é um fator determinante para o fornecimento irregular, entretanto, destacam que a precariedade do abastecimento apesar dos três reservatórios gera insegurança hídrica levando a questionar por que alguns são "possuidores" e outros são "excluídos" do acesso à água potável?.

A negação ao direito da população local a uma cidade sustentável e ao uso pleno à agua, reforça que as ações das ecofeministas, mulheres manobristas, promovem a sustentabilidade e preservação do equilíbrio ambiental da comunidade mesmo que seja ainda de forma precária. Segundo Piscitelli (2012) há estreita conexão entre os movimentos de mulheres e os ecológicos, questionando não apenas os grandes modelos políticos e econômicos, mas denunciando as relações opressivas que evidenciam os mecanismos de poder que estavam por trás do racismo, do sexismo e da postura irresponsável da humanidade para com o meio ambiente.

A negação plena ou parcial ao acesso da Comunidade da Rocinha à agua, fere frontalmente o artigo 225 da Constituição brasileira de 1988 que estabelece, todos têm direito ao meio ambiente ecologicamente equilibrado, bem de uso comum do povo e essencial à sadia qualidade de vida, impondo-se ao Poder Público e à coletividade o dever de defendê-lo e preservá-lo para as presentes e futuras gerações.Ainda que a água seja um serviço ambientalmente ativo como condição para existência de todo tipo de vida, não é possível extrair deste dispositivo legal a afirmação de um direito à água no ordenamento constitucional brasileiro.

O Conselho de Direitos Humanos (CDH) em setembro de 2010 aprovou por consenso sobre os direitos humanos e acesso à água potável e ao saneamento. No artigo 3, o direito humano à água potável e ao saneamento é derivado do direito ao adequado padrão de vida e é relacionado ao direito ao mais elevado padrão de saúde física e mental, bem como ao direito à vida e à dignidade humana. No artigo 6, o CDH reafirma que aos Estados cabe a responsabilidade primeira de assegurar a plena realização de todos os direitos humanos e que a delegação do serviço de abastecimento ou de saneamento a uma terceira parte não isenta os Estados das suas obrigações, mas reconhecendo o envolvimento dos atores não estatais na prestação dos serviços de abastecimento e de saneamento. No artigo 8, os Estados deverá desenvolver legislação, planejamento e estratégias para a progressiva realização das suas obrigações relacionadas ao acesso à água assegurando a transparência na implementação do serviço e a participação das comunidades locais e de relevantes patrocinadores conhecidos por stakeholders, monitorando as regulamentações legais e aplicando penalidades para violações de direitos humanos.

O risco sanitário e ambiental a que a Comunidade da Rocinha permanece exposta nos espaços cotidianos da vida humana deve ser tratado prioritariamente, com o desenvolvimento da interface saúde-ambiente envolvendo a implementação de políticas públicas através e ações interativas entre a promoção da boa qualidade ambiental e a promoção da saúde humana. Essa não é apenas uma demanda dos grupos de moradores, mas um direito, o direito à cidade sustentável, oficial, inclusiva, igualitária e participativa. 


\section{CONCLUSÕES}

Sem as obras de ampliação do abastecimento de água pela CEDAE, sem a retomada do"Programa Comunidade Cidade" pelo Estado, a atuação das mulheres manobristas deverão perdurar por longo período.

Imperioso um ponto final na invisibilização das mulheres como produtoras e sujeitos políticos e a extinção do dualismo que segrega os gêneros com a desconstrução do mito da natureza superior masculina ou humana, perante as demais formas de vida.

Os postulados éticos das ecofeministas precisam ser mantidos com firmeza, colocando o ser humano em uma perspectiva não androcêntrica, mas sim em relação de igual importância perante todas as formas de vida advindo da relevante conexão fisiológica das mulheres com o nascimento e nutrição dos seres humanos, de modo mais intenso do que os homens.

As mulheres têm a capacidade de promover uma revolução ecológica de forma que o colapso ambiental eminente não prejudique ainda mais os que estão em situação de vulnerabilidade, tanto pessoas como o meio ambiente em geral.

\section{REFERÊNCIAS}

DA SILVA, Lorena Duarte. As Favelas: Sua grandeza e seu potencial econômico. Revista Pet Economia UFES , v. 1, n. 2, pág. 53-59, 2020.

D'EAUBONNE, Françoise. Le féminisme ou la mort . Le passager clandestin, 2020.

FLORES, Joaquin Herrera. Direitos humanos, interculturalidade e racionalidade de resistência. Sequiência Estudos Jurídicos e Políticos. 2002.

GIL, Antonio Carlos. Como elaborar projetos de pesquisa. 5a. Ed. São Paulo: Atlas, 2010.

KUHN, Bárbara. Redes sociais e ecofeminismo: ferramentas de uma educação ambiental transformadora. 2018.

MERLO, Suzane Girondi Culau; CALGARO, Cleide. DO ECOFEMINISMO AO ECOHUMANISMO PARA O FIM DAS HIERARQUIAS DE GÊNERO E SEXUALIDADE. Revista de Estudos Jurídicos UNESP, v. 23, n. 38, 2021.

PIRES DO RIO, G A et. al. Política nacional de gestão de águas: há lugar para as cidades-região? Anais do XII Simpósio Nacional de Geografia Urbana, Belo Horizonte, novembro de 2016.

PISCITELLI, Adriana. Feminismos y Prostitución en Brasil: una lectura a partir de la antropología feminista. Cuad. antropol. soc.,Buenos Aires , n. 36, p. 11-31, dic. 20122012.

RODRIGUES, Karla Cristina Tyskowski Teodoro; VENSON, Auberth Henrik; DA CAMARA, Marcia Regina Gabardo. Distribuição espacial do acesso aos serviços de saneamento básico nas microrregiões brasileiras de 2006 a 2013. Revista brasileira de gestão e desenvolvimento regional, v. 15, n. 1, 2019.

SANTOS, M. Território globalização e fragmentação. São Paulo: Hucitec, 1994.

SWYNGEDOUW, Erik \& COOK, I. Cidades, coesão social e o meio ambiente: justiça urbana ambiental ou ecologia POLITICA?. Tensão entre justiça ambiental e justiça social na América Latina: o caso da gestão da água, p. 67, 2017. 